\section{Other Recent Earthquakes}

SEveral severe earth tremors and moderate to strong earthquakes have also been experienced recently in widely separated areas in Italy. On January 25 a severe tremor was felt at Genoa in Italy. This did no damage. On February 1, early in the day, a severe earthquake shock caused considerable damage to the famous cathedral town of Siena in Italy. A less severe shock was felt at Florence, and, presuming it was the same earthquake, the epicentre was close to Siena (lat. $43^{\circ} 20^{\prime} \mathrm{N}$., long. $11^{\circ} 20^{\prime}$ E.) On the same morning three shocks were felt in Bucharest, in Rumania. No damage was done. The epicentre of this earthquake was estimated in Bucharest to have been in the Black Sea, five hundred miles east of Bucharest.

\section{Earthquake Recorded on Magnetograph}

IN Earthquake Notes, the publication of the Eastern Section of the Seismological Society of America (11, Nos. I and 2, September 1939), it is stated that the earthquake with epicentre latitude $20 \cdot 8^{\circ} \mathrm{N}$., longitude $66 \cdot 0^{\circ} \mathrm{W}$. on June 12,1939 , which was felt in San Juan, was recorded at the San Juan Magnetic Observatory. The recording was on the magnetograms of both the declination and the horizontal intensity instruments, but there was no trace of a disturbance on the vertical intensity magnetogram.

\section{Francis Amory Septennial Prize}

IN compliance with the provisions of the will of the late Francis Amory, the American Academy of Arts and Sciences, as trustee of a fund given by the testator, announces a prize to be known as "The Francis Amory Septennial Prize", to be awarded for conspicuously meritorious work performed during the immediately preceding septennial period, "through experiment, study or otherwise, in the treatment and cure of diseases and derangement of the human sexual generative organs in general, and more especially for the cure, prevention or relief of the retention of urine, cystitis, prostatitis, etc." If any work of quality warrant it, the first award will be made in 1940 . The total amount will exceed 10,000 dollars, which may be divided at the discretion of the Academy among several nominees. While formal nominations are not expected and no essays or treatises in direct competition for the prize are desired, suggestions are invited. Communications should reach the Francis Amory Septennial Prize Award Committee not later than May 15, 1940, and should be addressed in care of the American Academy of Arts and Sciences, 28 Newbury Street, Boston, Mass., U.S.A.

\section{Paris International Trade Fair}

THe thirty-second annual Paris International Trade Fair will be held during May 11-27. The international aspect of the Fair will be developed to an even greater extent this year. Already national sections have been promised from Italy, Holland and Spain, as well as the usual displays from Switzerland, Belgium, etc. In deciding to hold the Fair this year at the Porte de Versailles, the Committee and exhibitors alike are showing the same courageous spirit as in 1917, when a similar decision was made although the German trenches were only 100 kilometres from the Capital.

An Inventions Competition is being organized, as usual, in connexion with the Fair. Last year 769 inventions were submitted by 517 competitors, representing fifteen countries. The value of the prizes this year will be 25,000 francs, as on previous occasions. In addition, there will be a number of medals, diplomas and prizes. Application forms, obtainable from the London office of the Fair at 17 Tothill Street, S.W.1, or direct from 23 rue N.D. des Victoires, Paris 2, must be returned not later than March 31 .

\section{Lectures at Marx House, London}

THE spring programme of lectures to be given by the Faculty of Science, Marx House, Clerkenwell Green, E.C.1, begins on February 12 when Prof. J. B. S. Haldane will give the first of a series of five lectures on "How the Human Body Works". In this course, which will run on consecutive Mondays at Marx House, Clerkenwell Green, at 7.30 p.m., Prof. Haldane will deal with "Is Man a Machine?" "Blood", "Digestion and Excretion", "The Nervous System" and "The Regulation of Bodily Functions". On February 16, Dr. P. Dienes will give the first of five lectures on "The Science of Thinking", in which he will deal with logic and arithmetic. These lectures, which will be at the University Labour Club, 15 Percy Street, W.1, will be held on consecutive Fridays at 8 p.m. Prof. J. D. Bernal is also to give a lecture, followed by a discussion, on "The Structure of Matter" on March 3. Further information can be obtained from the Secretary, Marx Memorial Library and Workers' School, Marx House, Clerkenwell Green, E.C.1.

\section{Announcements}

The National Association for the Prevention of Tuberculosis has decided to devote its activities in war-time chiefly to propaganda and the care and rehabilitation of tuberculous patients and their families.

Prof. John F. Fulton, professor of physiology in the Yale University School of Medicine, has been requested by Mrs. Cushing to write a biography of her husband, the late Dr. Harvey Cushing. Dr. Fulton will be grateful for letters, anecdotes or other pertinent material available.

THe Langley memorial prize, value $£ 21$, is open for competition among officers of the Colonial Medical Service who are serving or have served in West Africa, and will be awarded for the best paper on one of the following subjects: $(a)$ tropical medicine or surgery, (b) tropical hygiene and sanitation, (c) tropical entomology and parasitology. Papers, which may consist of published or unpublished work, should be sent to the Secretary, London School of Hygiene and Tropical Medicine, Keppel Street, Gower Street, W.C.1, by October 1. 